\title{
Determination of Equilibrium Constants for Binding of Acridine Orange and Its 10-Alkyl Derivatives to Dissolved Humic Substances by a Fluorescence Quenching Method
}

\author{
Kazuya OHga*, Tohru Tsuruhara*, Naoyoshi Egashira* and Tatsuaki KuroI** \\ * Department of Environmental Chemistry and Engineering, Faculty of Engineering, Oita University, \\ Oita 870-11, Japan \\ **Chemical Institute, Faculty of Education, Oita University, Oita 870-11, Japan
}

\begin{abstract}
Fluorescence intensities of Acridine Orange and its 10-alkyl derivatives were reduced by the presence of commercial humic acid or dissolved humic substances obtained from river water, seawater and pond water samples. Synchronous changes in the absorption spectra and the virtually unchanged fluorescence lifetime of the 10-dodecyl derivative suggested that the fluorescence quenching could be explained on the basis of a static quenching mechanism, in which the fluorescence dyes were bound to humic substances to form non-fluorescent dye aggregates. Curve fitting procedures for the upwardly-curved Stern-Volmer plots yielded the equilibrium binding constants normalized to organic carbon content. The binding constants at $\mathrm{pH} 7.0$ for fractions eluting at $\mathrm{pH} 2.4-7.5$ in a pH-gradient chromatographic separation of the aquatic humic substances were larger than those for fractions eluting at $\mathrm{pH} 8.2-$ 11.4. Some chemical properties of the binding have also been discussed in terms of the electrostatic interaction and/or the hydrophobic interaction.
\end{abstract}

Keywords Equilibrium binding constant, aquatic humic substance, humic acid, Acridine Orange dye, static fluorescence quenching

One of the important chemical properties of humic substances, which are a major fraction of dissolved organic carbon (DOC) in natural water ${ }^{1}$, is an ability to enhance water solubility values of hydrophobic organic contaminants such as polycyclic aromatic hydrocarbons and polychlorinated pesticides ${ }^{2,3}$, through an action of hydrophobic moieties within the polymer matrix. The binding of the hydrophobic compounds to aquatic humic substances has been investigated in detail using equilibrium dialysis ${ }^{4}$, reverse-phase separation ${ }^{5}$ and fluorescence quenching techniques; 6,7 it was primarily evaluated by determining partition coefficients.

On the other hand, humic substances can associate with cationic organic compounds as well, since they are negatively-charged polymers. For example, bipyridinium herbicides are bound to soil humic and fulvic acids $^{8}$ and are adsorbed on various cation-saturated humic acid particles. ${ }^{9}$ Absorption spectra of cationic aromatic dyes are changed by the presence of soil humic substances ${ }^{10}$, though mechanistic details remain vague. Cationic surfactants have been listed as organic compounds which are bound to humic substances in the environment. ${ }^{11}$ It is also interesting that trioctylamine in chloroform has been used to extract aquatic humic substances ${ }^{12}$, probably through formation of hydrophobic ion pairs. In this paper, we report a spectrophotometric study on the binding of Acridine

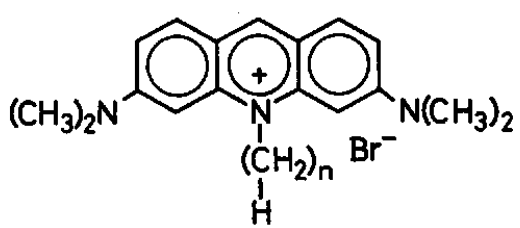

Fig. 1 Acridine Orange $(n=0)$ and its 10 -alkyl derivatives.

Orange (3,6-bis(dimethylamino)acridine, AO) and its 10-alkyl derivatives (Fig. 1) to commercial humic acid or aquatic humic substances. The primary purpose of the present study was to establish a fluorescence quenching method for determining the equilibrium binding constant (partition coefficient). Modes of the binding have also been discussed on the basis of the obtained binding constants.

AO is known as a metachromatic dye which can be bound to biological and synthetic polyelectrolytes. ${ }^{13}$ The binding to deoxyribonucleic acid (DNA) has aroused great interest since the dye exhibits a mutagenic activity. ${ }^{14}$ From an environmental point of view as well, interaction of $\mathrm{AO}$ or other cationic dyes with anionic humic polyelectrolytes would likely be one of the factors which should be paid attention to in fundamental researches concerning chemical and biolo- 
gical impacts of effluents from dyeworks on receiving waters.

\section{Experimental}

\section{Reagents}

AO base (Aldrich Chemical Company) was purified by a method described in the literature ${ }^{15}$, after being pretreated by chromatography on alumina using chloroform as an eluent. The 10-dodecyl derivative of $\mathrm{AO}$ $\left(A O C_{12}\right)$ was purchased from Dojindo Laboratories and used without further purification. The butyl $\left(\mathrm{AOC}_{4}\right)$, hexyl $\left(\mathrm{AOC}_{6}\right)$ and octyl $\left(\mathrm{AOC}_{8}\right)$ derivatives were synthesized and purified according to the method described by Yamagishi et al. ${ }^{16}$

Humic acid (Aldrich Chemical Company) dissolved in a $0.1 \mathrm{M} \mathrm{NaOH}$ solution was reprecipitated by adjusting the $\mathrm{pH}$ to 1.0 with $\mathrm{HCl}$. After this reprecipitation procedure was repeated twice, the humic acid was suspended in deionized water and then dialyzed against deionized water using a Visking VT351 cellulose tube with a nominal molecular weight cutoff level of 3500 in order to remove $\mathrm{Cl}^{-}$. The purified humic acid (HA) was recovered by centrifugation and dried under vacuum; the elemental analysis gave $\mathrm{C}$ of $53.32 \%, \mathrm{H}$ of $4.13 \%, \mathrm{~N}$ of $2.00 \%$ and the ash content of $6.1 \%$. A stock HA solution was prepared by dissolving desired amounts of $\mathrm{HA}$ in $0.1 \mathrm{M} \mathrm{NaOH}$ and then diluting with water by a factor of 10 .

Water was purified with both a Millipore Milli-RO15 water purification system and an activated charcoal column. XAD-8 resin was purified according to Thurman and Malcolm ${ }^{17}$ and was stored in methanol. Tannic acid was purchased from Wako Pure Chemical Industries Ltd. and was used in its original condition. All other reagents were of reagent grade or better and used without further purification.

\section{Aquatic humic substances}

A river water sample $\left(3 \mathrm{dm}^{3}\right)$ was taken from the Oita River (Oita, Japan) about $7 \mathrm{~km}$ upstream from the river mouth. Water samples were also taken from a pond $\left(3 \mathrm{dm}^{3}\right)$ near the university and from the Oita harbor $\left(12 \mathrm{dm}^{3}\right)$, into which the Oita River runs. These water samples were filtered through a $0.5-\mu \mathrm{m}$ glass fiber filter (Toyo Roshi GC-50; pretreated at $400^{\circ} \mathrm{C}$ for $3 \mathrm{~h}$ ) and were then adjusted to $\mathrm{pH} 2.0$ with phosphoric acid. The respective acidified sample was pumped onto a XAD-8 column $(12 \mathrm{~mm}$ i.d. $\times 180 \mathrm{~mm})$ at a rate of $1.0 \mathrm{~cm}^{3} \mathrm{~min}^{-1}$. The humic substances adsorbed were eluted with $0.1 \mathrm{M} \mathrm{NaOH}\left(100 \mathrm{~cm}^{3}\right)$ after the column was washed with $0.01 \mathrm{M}$ phosphoric acid $\left(50 \mathrm{~cm}^{3}\right)$. The column effluent was again adjusted to $\mathrm{pH} 2.0$ with phosphoric acid and pumped onto a smaller XAD-8 column $(10 \mathrm{~mm}$ i.d. $\times 90 \mathrm{~mm})$ at a rate of $0.5 \mathrm{~cm}^{3} \mathrm{~min}^{-1}$. The readsorbed humic substances were separated into two fractions by a pH-gradient elution using the same apparatus as described previously: ${ }^{18}$ the first fraction $\left(34 \mathrm{~cm}^{3}\right)$ was collected at $\mathrm{pH} 2.4-7.5$ (fraction I) and the second fraction $\left(34 \mathrm{~cm}^{3}\right)$ was collected at pH $8.2-11.4$ (fraction II). The pH-gradient solution was prepared by titrating $0.01 \mathrm{M}$ phosphoric acid with $0.01 \mathrm{M}$ trisodium phosphate and was passed through the column at a flow rate of $0.55 \mathrm{~cm}^{3} \mathrm{~min}^{-1}$.

\section{Apparatus}

Fluorescence and UV-VIS absorption spectra were recorded on a Shimadzu RF-510 spectrometer and a JASCO UVIDEC-610A spectrophotometer, respectively. $\mathrm{pH}$ values were measured with a TOA HM-5B $\mathrm{pH}$ meter. The DOC values of the humic fractions from the natural water were determined with a JASCO 524 total carbon analyzer. Fluorescence lifetime measurements were made with a PRA nanosecond timeresolved fluorescence spectrophotometer based on a single-photon counting technique. The light source was a hydrogen-filled $(0.5 \mathrm{~atm})$ flash lamp thyratron-triggered at $c a .33 \mathrm{kHz}$. Data of exciting flash lamp profiles and fluorescence decay curves accumulated on a Norland MCA IT-5300 multichannel analyzer were transferred to a NEC PC-9801 Vm computer through a EIA/RS-232 C connector.

\section{Changes in the dye absorption spectra}

An aliquot of the stock HA solution $\left(5-10 \mathrm{~mm}^{3}\right)$ was added to a $1 \times 1 \times 4 \mathrm{~cm}$ cell containing a dye solution $\left(3 \mathrm{~cm}^{3}\right)$ in $0.01 \mathrm{M}$ phosphate buffer (pH 7.0) and was then rapidly mixed. The cell had been previously thermostated at $25 \pm 1^{\circ} \mathrm{C}$. The buffer contained $10 \mathrm{v} / \mathrm{v} \%$ methanol unless otherwise noted. An initial decrease in the absorbance of $\mathrm{AOC}_{12}$ due to adsorption to the walls of the cell could not be depressed even by the addition of the $10 \%$ methanol. Thus, the dye solution was allowed to stand in the cell for at least $12 \mathrm{~h}$ prior to the addition of the HA solution. The concentration of $\mathrm{AOC}_{12}$ in the preequilibrated solution was estimated from Beer's law: the molar absorptivity $\left(6.25 \times 10^{4} \mathrm{M}^{-1}\right.$ $\mathrm{cm}^{-1}$ ) at $\lambda_{\max }$ of $496 \mathrm{~nm}$ was determined by using the limiting absorbance, which was obtained by extrapolation of a linear $-\ln \left(A_{t}-A_{\mathrm{e}}\right)$ vs. time plot to zero time, where $A_{t}$ and $A_{\mathrm{e}}$ are the absorbances at time $t$ and at equilibrium, respectively.

Association of the dyes with the added HA attained equilibrium within less than $3 \mathrm{~min}$. Absorption spectra were recorded for the equilibrated solutions. This addition/spectral measurement step was repeated until a total of five to ten aliquots of HA had been added. The same procedure was carried out also in the cases of addition of the aquatic humic fractions. In order to avoid any dimerization of the dyes ${ }^{13}$, the dye concentrations were kept lower than $3 \mu \mathrm{M}$ throughout this work.

\section{Fluorescence quenching experiments}

The fluorescence spectra of the dye solutions were taken in a $1 \times 1 \times 4 \mathrm{~cm}$ quartz fluorescence cell according to the same procedure as was used in the measurements of the absorption spectral changes. The excitation 
wavelength was $460 \mathrm{~nm}$. Quenching of the dye fluorescences was quantified as the ratio of $I_{0} / I$, where $I_{0}$ is the fluorescence intensity at $\lambda_{\max }$ of $517 \mathrm{~nm}$ when no humic substances are present and $I$ is the intensity when humic substances are present. The fluorescence intensities were corrected for the inner filter effect according to Gauthier et al.; ${ }^{6}$ the correction factors were not more than 1.15 .

\section{$p H$ effects on quenching of the $A O C_{12}$ fluorescence}

The two humic fractions from the river water sample were used as quenchers. Each fraction was diluted with an $\mathrm{NaOH}$ or phosphoric acid aqueous solution in order to obtain the desired pHs, and was then added to an $\mathrm{AOC}_{12}$ methanolic solution. The sample solutions were allowed to stand for $12 \mathrm{~h}$ prior to taking the fluorescence spectra.

\section{Fluorescence lifetime measurements}

Fluorescence intensities were monitored at $\lambda_{\max }$ of $517 \mathrm{~nm}$. The optimized lifetimes were determined by superimposing the curves due to convolution integrals, which were computed with the flash lamp profiles, on the observed fluorescence decay curves, checking the weighed residuals. All the measurements were carried out at room temperature using sample solutions prepared by the same method as in the measurements of the fluorescence spectra. The lifetime of $\mathrm{AO}$ ( $1.75 \pm 0.05 \mathrm{~ns}$ ) obtained in the absence of humic substances was in good agreement with the value (1.7 ns in $5 \mathrm{mM}$ phosphate buffer at $23^{\circ} \mathrm{C}$ ) determined by Kubota and Steiner. ${ }^{19}$

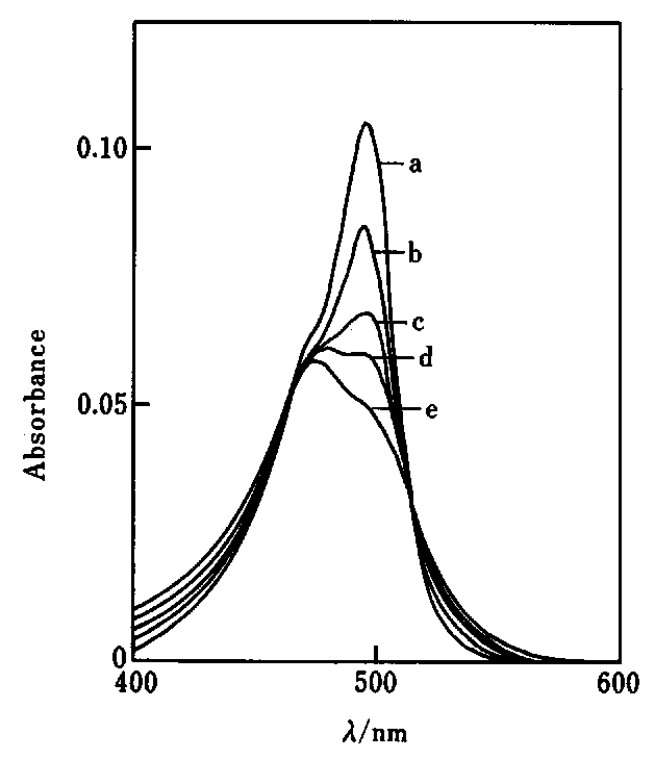

Fig. 2 Absorption spectra of $\mathrm{AOC}_{12}(1.7 \mu \mathrm{M})$ in the presence of $\mathrm{HA}$ in $10 \%$ methanol/0.01 $\mathrm{M}$ phosphate buffer ( $\mathrm{pH} 7.0$ ). Concentrations of HA: a, 0; b, 0.0533; c, 0.107; d, 0.133; e, $0.160 \mathrm{mgC} \mathrm{dm}^{-3}$.

\section{Results and Discussion}

\section{Spectral changes}

Figure 2 shows typical absorption spectra obtained upon addition of $\mathrm{HA}$ to an $\mathrm{AOC}_{12}$ solution; similar spectral changes were observed with $\mathrm{AO}, \mathrm{AOC}_{4}, \mathrm{AOC}_{6}$ and $\mathrm{AOC}_{8}-\mathrm{HA}$ systems as well. A gradual substitution of the $\alpha$ free dye band with a broader band around $470 \mathrm{~nm}$ bears a striking resemblance to the spectral change of AO induced by its binding to DNA or synthetic anionic polyelectrolytes, which is known as the metachromatic effect. ${ }^{13}$ Further, the addition of HA induced marked decreases in the fluorescence intensities of the dyes, closely linking with the changes in the absorption spectra, as shown in Figs. 3 and 4,

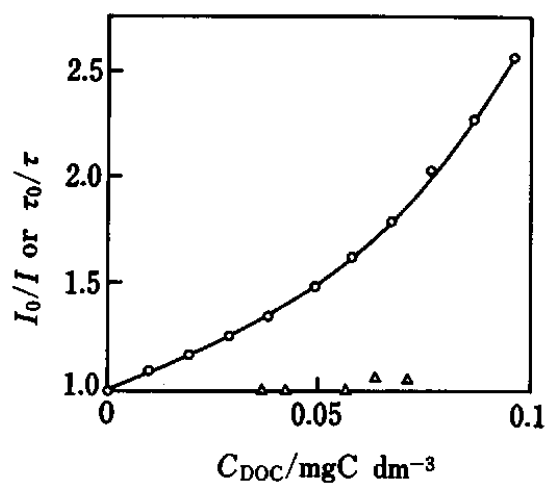

Fig. 3 Plots of $I_{0} / I(O)$ and $\tau_{0} / \tau(\Delta)$ vs. $C_{\mathrm{DOC}}$ in the $\mathrm{AOC}_{12-}$ HA system. $\tau_{0}$ and $\tau$ are the fluorescence lifetimes in the absence and presence of $\mathrm{HA}$, respectively. The concentration of $\mathrm{AOC}_{12}$ was $1.38 \mu \mathrm{M}$; $\tau_{0}$ was $1.37 \pm 0.05 \mathrm{~ns}$.

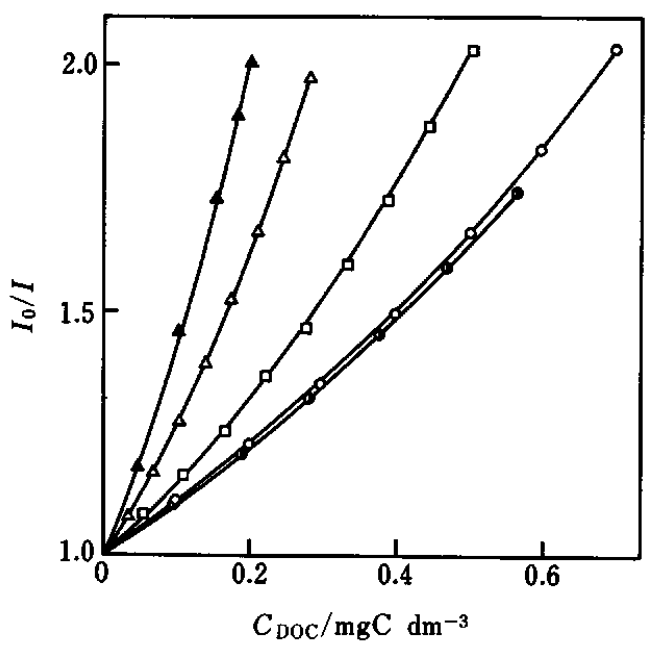

Fig. 4 Stern-Volmer plots for quenching of the fluorescence $\left(\lambda_{\max }=517 \mathrm{~nm}\right)$ of $\mathrm{AO}(\mathrm{O}), \mathrm{AOC}_{4}(O), \mathrm{AOC}_{6}(\square)$ and $\mathrm{AOC}_{8}$ $(\triangle)$ by $\mathrm{HA}$ in $10 \%$ methanol/0.01 M phosphate buffer $(\mathrm{pH}$ 7.0). Shaded triangles represent the data obtained with $\mathrm{AOC}_{8}$ in the buffer containing $0.05 \%$ methanol. The concentrations of the dyes were all $2.5 \mu \mathrm{M}$. 
where the HA concentration on the abscissa is expressed as $C_{\text {DOC }}$, the DOC calculated from the carbon content. The HA fluorescence was negligible as compared to the dye fluorescences.

The $\mathrm{AOC}_{12}$ fluorescence was not much altered by addition of low-molecular-weight organic compounds (hydroquinone, vanillin, salicylic acid and propionic acid of $1 \times 10^{-5} \mathrm{M}$ ) whose structures are included in constituents of humic substances. ${ }^{20}$ But it was quenched by tannic acid, which is a mixture of highmolecular-weight compounds having analogous molecular structures to those of humic substances, though with a lower quenching efficiency: $I_{0} / I$ values were 1.11 and 2.67 with 0.02 and $0.2 \mathrm{mg} \mathrm{dm}^{-3}$ of tannic acid, respectively, when the $\mathrm{AOC}_{12}$ concentration was 0.86 $\mu \mathrm{M}$. Accordingly, the spectral changes in the present HA systems would be explained on the basis of an analogous mechanism to that in the above-mentioned metachromatic AO-polyelectrolyte systems; that is, a binding of the dye molecules to the humic polymers would raise the local concentrations of the dyes, resulting in a ready formation of stacked dye aggregates. In addition, the result that the shapes and positions of the dye fluorescence spectra were little affected by the presence of HA appears to indicate that the ground-state dye aggregates are almost non-fluorescent.

\section{Determination of binding constants}

The Stern-Volmer plots of $I_{0} / I$ vs. $C_{\mathrm{DOC}}$ in Figs. 3 and 4 were curved upwards. In general, fluorescence quenching can be classified into two types: one is static quenching and the other is dynamic. ${ }^{6,21-24}$ The present AO dyes-HA systems undoubtedly include static quenching due to the dye aggregate formation. Also, since the fluorescence lifetimes of the dyes were quite short $\left(1.75 \pm 0.05 \mathrm{~ns}\right.$ for $\mathrm{AO} ; 1.37 \pm 0.05 \mathrm{~ns}$ for $\left.\mathrm{AOC}_{12}\right)$ and moreover the concentrations of the HA added were exceedingly low, it would be unreasonable to explain the positive deviations from the linear Stern-Volmer plot in terms of the coexistence of dynamic quenching, assuming that the quenching process is diffusioncontrolled. In fact, as shown in Fig. 3, the fluorescence lifetime of $\mathrm{AOC}_{12}$ was little affected by the presence of HA within the HA concentration range examined. This suggested that, at least in the $\mathrm{AOC}_{12}$ system, the fluorescence quenching substantially consisted of the static quenching, which is shown in Scheme 1. Here,

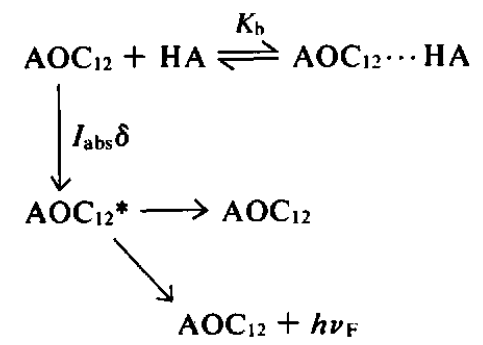

Scheme 1
$\mathrm{AOC}_{12} *$ is the excited singlet state of $\mathrm{AOC}_{12}$ which may be converted to the ground state through both radiative and non-radiative processes; $I_{\text {abs }}$ is the rate of absorption of photons by $\mathrm{AOC}_{12}$ in the absence of $\mathrm{HA}$. The non-fluorescent dye aggregates are formed inside the ground-state $\mathrm{AOC}_{12} \cdots \mathrm{HA}$ complex. The binding of $\mathrm{AOC}_{12}$ by $\mathrm{HA}$ may be described by a binding constant, $K_{\mathrm{b}}=\left[\mathrm{AOC}_{12} \cdots \mathrm{HA}\right] /\left[\mathrm{AOC}_{12}\right][\mathrm{HA}]$, where $\left[\mathrm{AOC}_{12} \cdots \mathrm{HA}\right]$ and [HA] represent the concentrations of the bound $\mathrm{AOC}_{12}$ and vacant binding sites, respectively. The decrease in the concentration of free $\mathrm{AOC}_{12}$ ([AOC $\left.\mathrm{AO}_{12}\right]$ ) which is induced by the binding is accompanied by the reduction of the light absorption to $I_{\text {ahs }} \delta$.

An analogous argument to that of Gauthier et al. ${ }^{6}$ or Moon et al. ${ }^{22}$ gives the following equation, which has the form of the Stern-Volmer equation, on the assumption that the fluorescence intensity is proportional to the concentration of free $\mathrm{AOC}_{12}$ in solution:

$$
I_{0} / I=1 / \delta=1+K_{\mathrm{b}}[\mathrm{HA}]
$$

If a significant excess of the quencher $\mathrm{HA}$ is present, [HA] can be approximated to correspond to the total concentration of the quencher added. This type of situation happens in quenching of polycyclic aromatic hydrocarbon fluorescences by humic substances. ${ }^{6,7}$ As seen in Fig. 3, however, small amounts of HA efficiently quenched the $\mathrm{AOC}_{12}$ fluorescence and thus the approximation may not be applied to the present system. In such a situation,

$$
\begin{aligned}
{[\mathrm{HA}]=} & \left\{-\left(K_{\mathrm{b}} C_{\mathrm{A}}-K_{\mathrm{DOC}} C_{\mathrm{DOC}}+1\right)\right. \\
& +\left[\left(K_{\mathrm{b}} C_{\mathrm{A}}-K_{\mathrm{DOC}} C_{\mathrm{DOC}}+1\right)^{2}\right. \\
& \left.\left.+4 K_{\mathrm{DOC}} C_{\mathrm{DOC}}\right]^{1 / 2}\right\} / 2 K_{\mathrm{b}} .
\end{aligned}
$$

Here, $C_{\mathrm{A}}$ is the total stoichiometric concentration of $\mathrm{AOC}_{12} ; K_{\mathrm{DOC}}$ is the binding constant normalized to the organic carbon content of the dissolved HA. $K_{\text {DoC }}$ is equal to $K_{\mathrm{b}} S$, where $S$ is the number of moles of the available binding sites per unit organic carbon content. Combining Eqs. (1) and (2) gives Eq. (3):

$$
\begin{aligned}
I_{0} / I= & 1+1 / 2\left\{-\left(K_{\mathrm{b}} C_{\mathrm{A}}-K_{\mathrm{DOC}} C_{\mathrm{DOC}}+1\right)\right. \\
& \left.+\left[\left(K_{\mathrm{b}} C_{\mathrm{A}}-K_{\mathrm{DOC}} C_{\mathrm{DOC}}+1\right)^{2}+4 K_{\mathrm{DOC}} C_{\mathrm{DOC}}\right]^{1 / 2}\right\} .
\end{aligned}
$$

The observed plots of $I_{0} / I$ vs. $C_{\text {Doc }}$ in Fig. 3 were analyzed with the aid of the Marquardt nonlinear leastsquares method. The parameters obtained, $K_{\mathrm{b}}$ and $K_{\text {Doc }}$, are listed in Table 1 . The same analysis of the data shown in Fig. 4 gave $K_{\text {DOC }}$ values of $2.9,2.3,4.6$ and $8.3 \mathrm{dm}^{3} / \mathrm{mgC}$ for $\mathrm{AO}, \mathrm{AOC}_{4}, \mathrm{AOC}_{6}$ and $\mathrm{AOC}_{8}$, respectively, on the assumption of the nonparticipation of dynamic quenching. Solid lines in Figs. 3 and 4 represent the $I_{0} / I$ values calculated from Eq. (3).

When pyrene was used as a neutral fluorophore, the system gave a $K_{\text {DOC }}$ of $0.085 \mathrm{dm}^{3} / \mathrm{mgC}$ according to the data treatment reported by Gauthier et al. ${ }^{6}$. This value was 34-times smaller than that for $\mathrm{AO}$, suggesting that electrostatic interaction played a significant role in 
Table 1 Parameters for the binding of $\mathrm{AOC}_{12}$ to humic substances in $10 \%$ methanol/0.01 M phosphate buffer $\ln 7$ n) $^{a}$

a. Fractions I and II of aquatic humic substances were collected at $\mathrm{pH} 2.4-7.5$ and at $\mathrm{pH} 8.2-11.4$ in $\mathrm{pH}$-gradient elution from a XAD-8 resin column, respectively.

the present cationic dye systems. On the other hand, it is important to note that $K_{\mathrm{DOC}}$ for the AO dyes increased with an increase in the length of the alkyl chain except for $\mathrm{AOC}_{4}$ (vide supra). The extents of change in the absorption spectra were also in the same order, when the spectra were taken at a fixed HA concentration. It is known that the affinity for binding of hydrophobic organic solutes to humic substances increases with an increase in the hydrophobicity of the solute $^{3-5}$, and moreover, it has been reported that $\mathrm{AO}$ derivatives with longer 10-alkyl chains have dimerization-equilibrium constants more enlarged by hydrophobic interaction between the alkyl chains ${ }^{16,25}$, if the alkyl groups are longer than the hexyl one. Thus, it is probable that the effect of the alkyl group on the $K_{\mathrm{DOC}}$ resulted from the enhanced hydrophobic interactions in both the binding to HA and the self-association of the bound dyes in the polymer domains. This significance of hydrophobic interaction was supported by the fact that reduction of the methanol content in the buffer solution from $10 \%$ to $0.05 \%$ enhanced the quenching efficiency in the $\mathrm{AOC}_{8}$ (Fig. 4). The smaller $K_{\mathrm{DOc}}$ for $\mathrm{AOC}_{4}$ would be attributable to a more predominant steric hindrance due to the butyl group than due to the hydrophobic effect, in analogy with the case of the dimerization equilibrium..$^{25}$

A $S$ value of 11 for the $\mathrm{AOC}_{12}-\mathrm{HA}$ system signified that HA contained about 8 carbon atoms per unit binding site. In addition, calculations of [HA] by using Eq. (2) showed that, in the case of $\mathrm{AOC}_{12}$, the available binding sites of $83 \%$ or above were occupied by the dye molecules under the conditions in Fig. 3; even in the case of AO having the smallest $K_{\text {Doc }}$ (Fig. 4), more than $49 \%$ of the sites was occupied. Such a dense occupancy might account for the results that the socalled $\gamma$ absorption bands ${ }^{13}$ due to the dye aggregates were observed, whereas absorption bands due to bound monomeric and/or dimeric species were not.

\section{Fluorescence quenching by aquatic humic substances}

Figure 5 shows Stern-Volmer plots for quenching of the $\mathrm{AOC}_{12}$ fluorescence by aquatic humic substances which were fractionated using a $\mathrm{pH}$-gradient elution technique. Fluorescences from the humic fractions were negligible and the humic fractions were confirmed not to affect the $\mathrm{AOC}_{12}$ fluorescence lifetime. Changes in the absorption spectrum by the addition of the humic fractions were also analogous to those obtained by the addition of HA. Further, the fluorescence spectrum was little altered by addition of several inorganic ions $\left(\mathrm{NaCl}, \mathrm{CaCl}_{2}, \mathrm{MgCl}_{2}\right.$ and $\mathrm{NaNO}_{3}$ of $5.0 \times 10^{-4} \mathrm{M}$; $\mathrm{Na}_{2} \mathrm{SO}_{4}$ of $1.0 \times 10^{-3} \mathrm{M} ; \mathrm{CuCl}_{2}$ and $\mathrm{FeCl}_{3}$ of $5.0 \times 10^{-5} \mathrm{M}$ ) which were assumed to have got into the quencher solutions from the original water samples.

The parameters obtained by the same analysis as performed on the HA systems are summarized in Table 1. All of the humic fractions examined had far smaller $K_{D O C}$ values than that for HA. Analogous differences between aquatic humic substances and commercial humic acids have been observed in the water solubility enhancement of chlorinated aromatic hydrocarbons by humic substances, and have been attributed to the higher content of nonpolar molecular moieties in commercial humic acids. ${ }^{2}$ Thus, the results in this study would also be explained in terms of reduced hydrophobic interaction with the aquatic humic substances. In other words, electrostatic interaction may be assumed to contribute to the binding to the aquatic humic substances more highly than to the binding to HA. In addition, these results substantiated the warning given by Malcolm and MacCarthy ${ }^{26}$ that commercial humic acids are not representative of

Fig. 5 Stern-Volmer plots for quenching of the fluorescence of $\mathrm{AOC}_{12}(0.82 \mu \mathrm{M})$ by aquatic humic substances in $10 \%$ methanol/0.01 $\mathrm{M}$ phosphate buffer $(\mathrm{pH} 7.0)$. The aquatic humic substances used are fractions 1 and 11 of the river water $(O, \Theta)$, pond water $(\Delta, \boldsymbol{\Delta})$ and seawater $(\square, \square)$. Shaded marks represent the plots for fractions II. 
Fig. 6 Influences of $\mathrm{pH}$ on quenching of the $\mathrm{AOC}_{12}$ fluorescence by fractions $I(O)$ and II $(\Delta)$ from the river water. The concentration of $\mathrm{AOC}_{12}$ was $0.82 \mu \mathrm{M}$ : the DOC values of fractions I and II were 0.17 and $0.12 \mathrm{mgC} \mathrm{dm}^{-3}$, respectively.

aquatic humic substances.

As shown in Fig. 6, the quenching efficiencies by fractions I and II from the river water increased with an increase in $\mathrm{pH}$; the efficiency of fraction I remained nearly unchanged above $\mathrm{pH} 7$ and that of fraction II remained unchanged above $\mathrm{pH} 10$. Fraction $\mathrm{I}$ is a humic fraction eluting at $\mathrm{pH} 2.4-7.5$ from a hydrophobic XAD-8 resin column and fraction II is that eluting at $\mathrm{pH} 8.2-11.4$. Accordingly, as expected from the significant contribution of electrostatic interaction, the $\mathrm{pH}$ dependences appear to reflect titrations of the humic fractions with a base. Moreover, differences in $S$ between fractions I and II of all the water samples (Table 1) would also be accounted for at least in part by the electrostatic interaction, since the extents of ionization may be higher for fractions I at $\mathrm{pH} 7.0$ where the fluorescence quenching experiments were conducted. It should be noted here that the larger $S$ values for fractions I govern larger $K_{D O C}$ values for fractions $I$ in the cases of river and pond waters.

The authors are indebted to Professor T. Hano in Oita University for permitting us to copy a computer program on Marquardt's method. We also thank Mr. M. Yamato for his technical assistance. This work was supported by the Nippon Life Insurance Foundation.

\section{References}

1. E. M. Thurman, "Organic Geochemistry of Natural Waters", Chapt. 10, Martinus Nijhoff/Dr W. Junk Publishers, Dordrecht, 1985.

2. C. T. Chiou, D. E. Kile, T. I. Brinton, R. L. Malcolm, J.
A. Leenheer and P. MacCarthy, Environ. Sci. Technol., 21, 1231 (1987).

3. C. T. Chiou, R. L. Malcolm, T. I. Brinton and D. E. Kile, Environ. Sci. Technol., 20, 502 (1986).

4. Y. -P. Chin and W. J. Weber, Jr., Environ. Sci. Technol., 23, 978 (1989).

5. P. F. Landrum, S. R. Nihart, B. J. Eadie and W. S. Gardner, Environ. Sci. Technol., 18, 187 (1984).

6. T. D. Gauthier, E. C. Shane, W. F. Guerin, W. R. Seitz and C. L. Grant, Environ. Sci. Technol, 20, 1162 (1986).

7. T. D. Gauthier, W. R. Seitz and C. L. Grant, Environ. Sci. Technol., 21, 243 (1987).

8. S. U. Khan, Can. J. Soil Sci., 53, 199 (1973).

9. S. U. Khan, J. Environ. Quality, 3, 202 (1974).

10. S. K. Banerjee, K. B. Roy and S. C. Das, J. Indian Chem. Soc., 50, 549 (1973).

11. U. Müller-Wegener, "Humic Substances and Their Role in the Environment", ed. F. H. Frimmel and R. F. Christman, p. 190, John Wiley and Sons, New York, 1988.

12. S. H. Eberle and K. H. Schweer, Vom Wasser, 41, 27 (1974).

13. V. Vitagliano, "Aggregation Processes in Solution", ed. E. Wyn-Jones and J. Gormally, Chap. 11, Elsevier, Amsterdam, 1983.

14. N. Kure, T. Sano, S. Harada and T. Yasunaga, Bull. Chem. Soc. Jpn., 61, 643 (1988).

15. V. Vitagliano, O. Ortona and M. Parrilli, J. Phys. Chem., 82, 2819 (1978).

16. A. Yamagishi, T. Masui and F. Watanabe, J. Phys. Chem., 85, 281 (1981).

17. E. M. Thurman and R. L. Malcolm, Environ. Sci. Technol., 15, 463 (1981).

18. K. Ohga, Y. Aritomi and H. Ohtsu, Anal. Sci., 5, 215 (1989).

19. Y. Kubota and R. F. Steiner, Biophys. Chem., 6, 279 (1977).

20. R. F. Christman, D. L. Norwood, Y. Seo and F. H. Frimmel, "Humic Substances II. In Search of Structure", ed. M. H. B. Hayes, P. MacCarthy, R. L. Malcolm and R. S. Swift, Chap. 2, John Wiley and Sons, New York, 1989.

21. T. Morita, Bull. Chem. Soc. Jpn., 57, 1723 (1984).

22. A. Y. Moon, D. C. Poland and H. A. Scheraga, J. Phys. Chem., 69, 2960 (1965).

23. Y. Kubota, Y. Motoda, Y. Shigemune and Y. Fujisaki, Photochem. Photobiol., 29, 1099 (1979).

24. Y. Kusumoto, S. Ihara, J. Kurawaki and I. Satake, Chem. Lett., 1986, 1647.

25. A. Yamagishi and F. Watanabe, J. Phys. Chem., 85, 2129 (1981).

26. R. L. Malcolm and P. MacCarthy, Environ. Sci. Technol., 20, 904 (1986).

(Received August 15, 1990)

(Accepted September 13, 1990) 